Original article

\title{
Immediate and brief intervention after suicide attempts on patients without major psychiatric morbidity-A pilot study in northern Israel
}

\author{
Limor Givon $^{\mathrm{a}, *}$, Avi Levi ${ }^{\mathrm{a}}$, Boaz Bloch $^{\mathrm{b}}$, Eyal Fruchter ${ }^{\mathrm{a}}$ \\ ${ }^{a}$ Rambam Health Center, Technion, Haifa, Israel \\ ${ }^{\mathrm{b}}$ Emek Medical Center, Technion, Afula, Israel
}

\section{A R T I C L E I N F O}

\section{Article history:}

Received 11 November 2017

Received in revised form 5 January 2018

Accepted 8 January 2018

Available online 3 March 2018

\section{Keywords:}

Suicide

Suicide attempt

Suicide prevention

Crisis intervention

Emergency psychiatry

Public health

\begin{abstract}
A B S T R A C T
Background: Suicide Prevention is an ongoing task for mental health services. This article describes a pilot program for suicide prevention that took place in two districts in Israel from 2009 to 2012. The program targeted specific population, patients in high-risk for suicide, without major mental illness or previous association with the mental health system. In that group many suicide attempts were due to stressful life events.

Methods: Patients who performed a suicide attempt or were considered high-risk for suicide were referred to the project. The first contact took place up to $24 \mathrm{~h}$ after the referral and included a phone call with suggestion for further intervention. If he was willing, the patient was invited to a serious of 8-12 meetings with a therapist that focused on "crisis intervention" techniques.

Results: 212 subjects were referred to the project. Three quarters of the referrals were females. Most of them were of Jewish nationality, however, the percentage of Druze in the program's population was higher than their percentage of general population. Only 137 continued participation after the initial phone call, people of Jewish nationality were more willing to continue the intervention. During the intervention there was a decline in suicide rates in the participating districts.

Conclusions: The pilot program exhibits promising preliminary results, it is interesting to examine the difference in participation between different ethnic groups. Since the sample size is small, there is a need to continue the program on a larger scale.
\end{abstract}

(c) 2018 Elsevier Masson SAS. All rights reserved.

\section{Introduction}

Suicides and suicide attempts are a universal problem, which affects people of all ages, religions and nationalities. There are about 900,000 complete suicides, and between 9 and 36 million suicide attempts reported worldwide each year [1], and yet this data represent an underestimation, mainly due to the low report rate.

The definition of "complete suicide" is straightforward, meaning a death caused by self-directed injurious behaviour with an intent to die as a result of the behaviour [2]. When examining cases of complete suicide there are many important differences between them, such as age and gender of the victim, whether or not he suffered from major mental illness, the method and others [3].

It is more complex to define a suicide attempt. According to the CDC, a suicide attempt is defined as A "non-fatal, self-directed,

\footnotetext{
* Corresponding author at: 8 Eder street, Haifa, 3475227, Israel.

E-mail address: 1_givon@rambam.health.gov.il (L. Givon).
}

potentially injurious behaviour with an intent to die as a result of the behaviour; might not result in injury" [2]. Suicide attempts represent a spectrum of acts that differ in many aspects. Such differences include the method used, the seriousness of the intention to die, the chances of "failure" and others.

There are many risk factors for suicide and suicide attempts: demographic, medical, psychological and situational [4]. A previous suicide attempt is serious risk factors for repeated attempts. The suicide risk for males and females who have previously attempted suicide is reported to be as high as 55 and 77 times greater than that of the general male and female population, respectively [5]. A research from Israel showed that as many as 50\% of people who reattempted suicide did so in the three months following the first attempt [6]. Therefore, early intervention after suicide attempts can potentially prevent subsequent attempts and it needs to be as early as possible.

However, it is unclear what the best form of intervention is, after a suicide attempt, which, as noted before, is not a uniform "disease", but includes many different situations and behaviours with various levels of risk. Some suicide attempters suffer from major mental illness and will need hospitalization and intense 
psychiatric treatment, while others performed suicide attempts as an impulsive reaction to a stressful life event, but are otherwise mentally stable [7]. It is clear that there cannot be a "one size fits all" treatment program. An example for this complexity, could be found dealing with the question of hospitalizing the suicidal patient. Psychiatric hospitalization may reduce the risk in the short-term, since the patient will be in a controlled environment. However, hospitalization does not completely prevent suicide and a recent meta-analysis found the rates of inpatient suicides per patient-years to be higher in more recent studies, despite a shorter average length of hospital stay [3]. This finding can be explained by the understanding that hospitalization removes the patient from his natural support system and reduces his faith in his internal coping mechanism. The situation is even more complex if the hospitalization is involuntary. Such commitment can cause anger and resentment and shatter the trust between the patient and his therapist. There are many studies that demonstrated an increase in suicides after discharge from psychiatric hospitals [8-13], and until now, there is no evidence based data about the effectiveness of hospitalization in preventing long-term suicidal behaviour [14-16].

There have been many studies examining interventions developed to prevent subsequent suicide attempts. In a study performed by Fleishman et al., a brief intervention contact (BIC) that included follow up and patient education, lead to significant reduction in death from suicide [17]. A recent study from the United States showed that multifaceted intervention (that included brief intervention and a series of telephone calls after discharge) produced a meaningful reduction in the proportion of participants who attempted suicide over the 12 month observation period and a $30 \%$ reduction in the overall number of suicide attempts [18]. Another brief intervention program that included three therapy session and a follow up with a personalized letter, led to a decrease of $80 \%$ in repeated suicide attempts [19]. All those studied demonstrate that a brief and focused intervention can reduce the risk for repeated suicide attempts.

\subsection{Suicidality in Israel}

The suicide prevalence in Israel is 6:100,000 which add up to about four hundred suicides each year. This is lower than most western countries but higher than traditional Islamic countries, probably due to the higher percentage of traditional and religious population [20]. Three Quarters of all suicide victims are males. The suicide rate increases with age, with higher suicide rate in the elderly (over 75 years), although in that age groups suicide causes only $0.1 \%$ of the deaths. The prevalence of reported suicide attempts is estimated to be around 100:10,000 [21]. Among females, the prevalence is between 1.3-1.5 times higher than among males. The highest rates of suicide attempts are in the 1821 age group. In Israel, most young adults in that age group are in mandatory military service. The suicide attempts at this age are mostly in mild and are probably due to the stress of military service as well as potential secondary gain [22]. Although there were some small scale prevention programs, such as in the Israeli Defense Force (IDF) there was never an organized national effort for suicide prevention $[23,24]$.

The first encounter of patients who attempted suicide with the health care system usually takes place in the emergency rooms (ERs) of the general hospitals. Most suicide attempters will not be hospitalized in a psychiatric department and will be discharged after a brief intervention in the ER or a short hospitalization in the medical or surgical departments, and without any follow-up program. The paper will describe a pilot effort for a brief intervention program led by a national effort of suicide prevention and its results.

\section{Method}

The pilot program continued from January 2009 until December 2012. It took place in two districts within northern Israel: The Northern district and Haifa district. In both districts the population is ethnically diverse and includes Jewish and Arab populations (the Arab population includes Muslims, Christians and Druze). The project involved cooperation between the Ministry of Health, the Ministry of Social Services, the National Insurance Institute, Israel Trauma Coalition and "path to life", a non-profit organization devoted to suicide prevention. Unfortunately, we had access only to the data from the Haifa district.

\subsection{Goals of the program}

The project had therapeutic and organizational goals. The short-term goal was to provide an immediate and accessible therapeutic connection to people who attempted suicide, in order to reduce the rate of recurrent attempts and prevent suicides. A long-term goal was to create better communication and interface between different mental-health services; especially between the general hospitals, the psychiatric departments, and the community mental health services.

\subsection{Target population}

The project targeted a specific subgroup of population: people who attempted suicide or were at high risk of suicidal behaviour, did not exhibit a major mental illness (other than adjustment disorder) and were not treated by the mental health system. The rational for choosing this target population was based on the assumption, that in many cases, for this group, the suicide attempt was a reaction to stressful life events and therefore required an urgent crises intervention but not necessarily a long one. Those patients were often reluctant to turn to the public mental health system, and even when they decided to do so, the burden on the system caused long waiting period for treatment, thus making it impossible for them to receive prompt intervention, within the critical 3 months. As a result, many high-risk patients "fell through the cracks" and had to cope on their own, were hospitalized in psychiatric departments that were the only place where acute treatment was available or even ended up re- attempting suicide. Exclusion criteria were: 1) long history of major mental illness, 2) psychoactive substance abuse or dependence, 3 ) age under 18 years, 4 ) patient who were already treated in the Israeli mental health system, 5) IDF soldiers.

\subsection{The intervention processes}

In the Haifa district, the majority of the subjects were referred from the general hospitals in Haifa. Most of them were referred after a suicide attempt, but some were referred after a psychiatric examination that detected high risk for suicide. Before discharge from the hospital, the patients were informed about the program. Those who expressed interest signed a waiver of medical confidentiality. The project's main coordinator referred them to therapy according to their area of residence and cultural background. The first contact with each patient was a telephone call in the first $24 \mathrm{~h}$ after the suicide attempt. At this call if the patient agreed, the first intervention meeting was set up to three days after the attempt. The intervention consisted a series of about 12-15 sessions that focused on crisis intervention. After completion of the program, patients who needed additional therapy were referred appropriately. All the therapists that participated in the pilot program were licensed therapists with work experience in the mental health services with suicidal patients. The therapy was based on the principles of crisis intervention, specifically: identification and revealing of the trigger, 
recruitment of internal and external resources and interface with community services [25]. However, there was not a uniform protocol for the intervention and no specific training, and the professional experience of each therapist influenced the intervention.

\subsection{Tools and statistics}

We processed the data with a basic software (Excel), no elaborate statistical processing was done.

\section{Results}

The suicide-prevention pilot program took place between the years 2009-2012. According to data obtained from the Israeli Ministry of Health, 2639 suicide attempts of people older than 18 were reported in the Haifa district in those years. Recurring attempts by the same person were counted separately. In those four years, 212 patients were referred to the project in the Haifa district, representing less than ten percent of the total suicide attempts.

\subsection{Profile of the participants}

From the 212 referrals, 155 came from the only tertiary medical center in the district, Rambam health campus. In that medical center there is a twenty-four hours psychiatric emergency service with an attending psychiatrist during the day and a resident in psychiatry in the evening and night. Thus, each patient who reported or was suspected of committing a suicide attempt got a preliminary psychiatric evaluation, and, if he fulfilled the inclusion criteria, was offered to participate. Other referrals were from smaller hospitals in the district that did not have a psychiatric emergency service, and only 28 cases were referred from the community (some from primary care physicians and a few were self-referrals). Three quarters of the referrals were females. Sixty percent of the referrals were of Jewish nationality, 25\% were Arabs (Muslims and Christians) and 9\% were Druze.

Not all the subjects that were referred to the program eventually met with the therapist. Over a third of the subjects refused to continue the participation after the initial phone call (Table 1 ). When comparing the subjects who continued participation with those that declined, it is interesting to see that the ratio between male and female is equal in both groups. When dividing the subjects according to their ethnic group, it is noticeable that participation rates were lower in minority groups. From the Jewish population, which is the majority population in Israel, 70\% accepted the offer for intervention. From Arab (Christians and Muslims) and Druze Population, the percent of patients willing to participate was much lower (Fig. 1).

\subsection{Changes in suicide rates during the project years}

Data about complete suicide and suicide attempts in the region was received from the Israeli Department of Mental Health. The

Table 1

Comparison between profiles of subject who continued participation in the program vs. subjects that declined.

\begin{tabular}{llll}
\hline & Total & Continued & Declined \\
\hline $\begin{array}{l}\text { Subjects } \\
\text { Gender }\end{array}$ & 212 & $137(65 \%)$ & $75(35 \%)$ \\
$\begin{array}{l}\text { Male } \\
\text { Female }\end{array}$ & 53 & $34(64 \%)$ & $19(36 \%)$ \\
Ethnicity & 157 & 102 & 55 \\
Jewish & & & $38(30 \%)$ \\
Arab & 127 & $89(70 \%)$ & $22(42 \%)$ \\
Druze & 52 & $30(58 \%)$ & $10(53 \%)$ \\
Unknown & 19 & $9(47 \%)$ & 5 \\
\hline
\end{tabular}

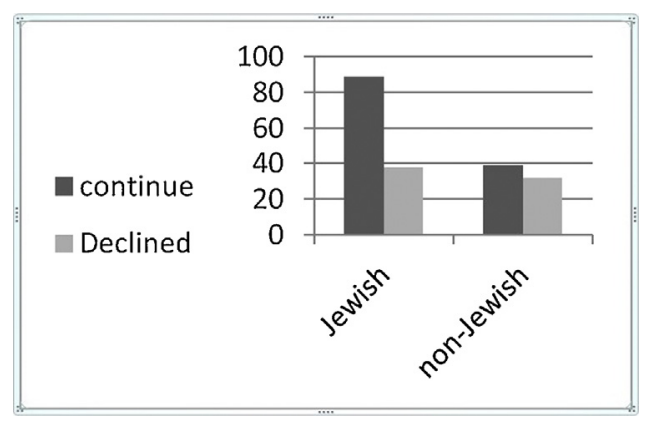

Fig. 1. Numbers of participants and decliners in different ethnic groups.

data included all suicide cases reported in people older than 18 years. There was a decline in complete suicide rates after 2009 in the districts that were included in the projects in comparison to other districts (Fig. 2).

When we look at the data on suicide attempts in the years before, during and after the pilot project, we see there was a continuous increase in suicide attempts in all the districts. In the northern district, the increase is lower than in districts that were not included in the project but in the Haifa district, the increase is even higher (Fig. 3). A possible explanation might be the higher registration and report of suicide attempts in the areas taking part in the project. This rise does not contradict the projects targets as it is influencing the actions taken after the attempt and not a prior prevention. It is important that none of the participants in the pilot programs have committed suicide during the project.

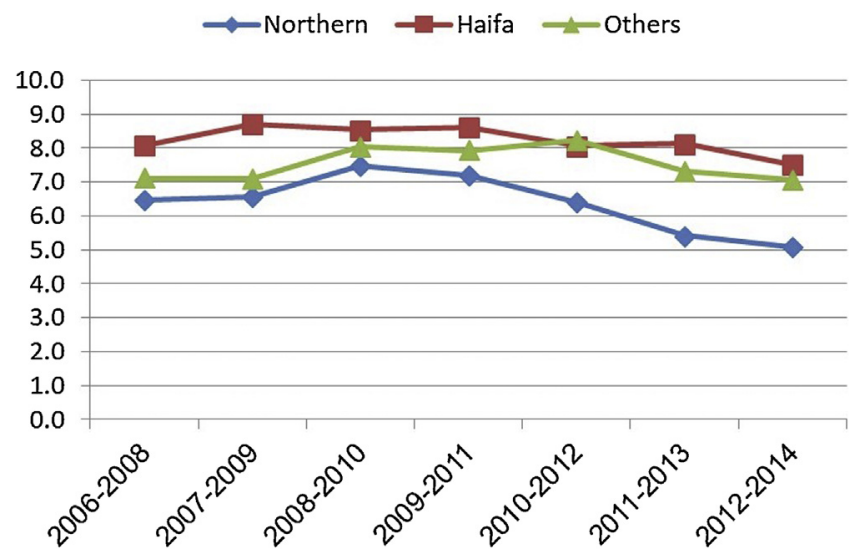

Fig. 2. Rates of complete suicides for 100,000 population in different districts.

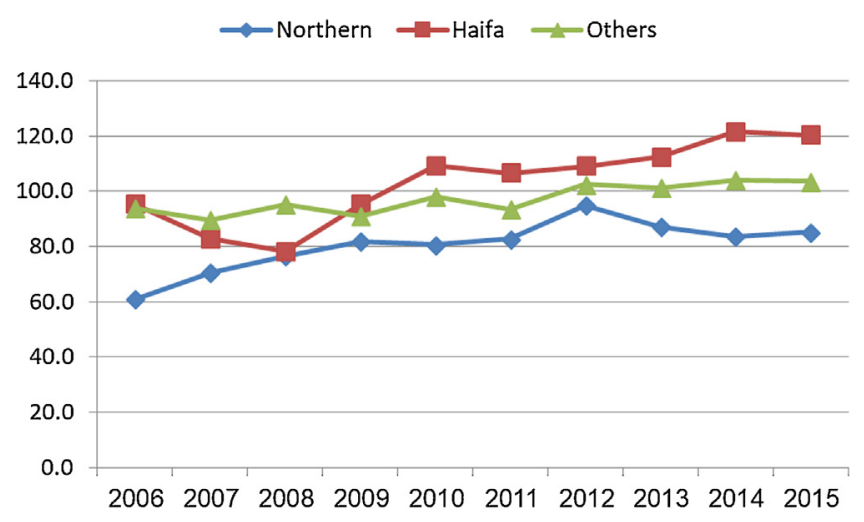

Fig. 3. Rates of suicide attempts for 100,000 population in different districts. 


\section{Discussion}

This article describes the outcomes in Haifa district of a pilot program for brief and immediate intervention in an un-treated, non-soldier population after a suicide attempt.

There were 212 referrals from Haifa district. This is less than $10 \%$ of total suicide attempts reported in the district in those years. Nevertheless, since most people referred to the intervention program came from the tertiary hospital, it probably means those were the more serious suicide attempts. The probable explanations for the low rates of participation, are the restrictive inclusion criteria, excluding all those in military service (as they are treated within the military mental health system) thus excluding most of the E.R. suicide attempt patients. A smaller, yet important explanation for the low inclusion rate, was reluctance by patients to sign the waiver necessary to enter the project.

Most of the referrals came from a tertiary medical center that includes twenty-four hours psychiatric emergency services. In this center, the psychiatric evaluation was only a few hours after the attempt, while in other hospitals the encounter with a mental health professional was usually more than a day after the attempt. It is possible that when your first contact with the patient is closer to the attempt he will be more willing to accept help.

The project focused on a less studied segment of suicide attempters - those without a major mental illness. In this group, in many cases, the suicide attempt was due to a stressful life event such as a family dispute or financial problems. Many participants described the attempt as a "cry for help", a way to communicate their distress to their family and community. Many were reluctant to turn to the mental health services due to fear of being stigmatized. On further investigation many of the patients had a history of stressful life events but were able to cope without therapeutic intervention until the event that caused the attempt.

The Majority of the referrals were females, which is expected, as they attempt suicide more often. It is interesting that almost ten percent from the referrals were of Druze, while they are only 2.5\% of the population in Haifa district. This might indicate an increased risk for suicide attempts in this population. A previous demographic study in minority groups in Israel showed an increase risk of complete suicide in the Druze population, but not of suicide attempts [26]. This assumption needs to be confirmed in future epidemiological studies.

Data received from the Israeli Ministry of health regarding complete suicides and suicide attempts rates, demonstrated a decline in complete suicides in the relevant districts in the years of the project, but not in suicide attempts. It is important to consider that in the same decade, a great effort was made to increase awareness for suicide attempts and many of the emergency rooms began to use a computerized system that simplified the recording and report of events; both factors contribute to the dramatic increase in reports about suicide attempts. The decline in complete suicide could be regarded as an indication for the success of the program to reduce suicide rates in high-risk populations, but it needs to be established with further studies that will compare between a group of patients that participated in our program and a control group.

From the 212 referrals, 75 declined to continue after the initial phone call with the therapist and did not attend any meetings. We do not have accurate data about the reasons for the decline but some stated that they will have technical difficulties attending the meetings and many of them said that they are no longer interested in further intervention. An important point to consider when we examine the participation rates is that sometimes a minimal intervention is sufficient to reduce risk for repeated suicide attempts [27]. It is possible that the first encounter in the emergency room and the follow-up phone call with an offer for further intervention provided the patients with an option; thus, reducing their sense of helplessness which is one of the triggers for repeated suicidal behaviour. This hypothesis needs verification in following studies.

When we examine the demographics of the patient who declined participation against those who continued participation, we can see that the ratio between males and females is similar in both groups. That is in contrast with the common finding that men are less likely to accept help than women [28-30]. This contradiction might be due to the relatively low number of participants but it might also imply a population change in relation to help seeking. People from the Arab and Druze minorities in Israel had lower participation rates than people from the Jewish majorly. The Arab population in Israel is more rural and less educated and people from this population are less likely to turn to mental health services, due to fear of stigma and lack of belief in the ability of psychotherapy to help [28,31]. The differences in help-seeking behaviour were known when the pilot project was designed, and the project coordinator tried to assign a therapist from similar cultural background who speaks the same language as the patient in an effort to reduce the dropout rates in those special populations. However, the difference in participation was still significant [32,33]. There is a need to develop different models of intervention for population who are reluctant to meet with a therapist such as community based outreach programs.

Our study had several substantial limitations. First, the sample size is small. The number of participant is less than $10 \%$ of all suicide attempts and those arriving to an intervention meeting was around $5 \%$ of all attempters. Another important limitation is that although the total suicide rate was in decline in the districts involved in the project, we do not have follow-up data on the actual group that participated in the study, so it is impossible to determine if the reduction is because of the program and it is likely that other factors were also involved. However, the promising preliminary data led to the reintroduction of the program this year. There was also no uniform therapeutic protocol for the intervention.

In conclusion, the pilot project was an organized program for urgent intervention after a suicide attempts in Israel. There are preliminary data for its effectiveness, but in order to establish it further there is a need to collect more data. In order to reach a higher percent of the suicide attempters, it is worth to reconsider the inclusion criteria in order to reach broader population. Our therapeutic program included an intervention of 12-15 therapeutic sessions. This might be a "too big commitment" for our target population that included people without major mental illnesses and can possibly be one of the reason that many people declined participation after the initial phone call. Previous studies have shown that shorter interventions were effective in reducing suicide attempts rates, with fewer costs. Finally, people from minority populations were more reluctant to participate in the therapy sessions, even when the therapist was from a similar cultural background. Those populations might benefit more from a completely different method of intervention; possibly community outreach programs which needs further investigation.

\section{Funding}

This research did not receive any specific grant from funding agencies in the public, commercial, or not-for-profit sectors

\section{References}

[1] Bertolote JM, Fleischmann A, Butchart A, Besbelli N. Suicide, suicide attempts and pesticides: a major hidden public health problem. Bull World Health Organ 2006;84:260 S0042-96862006000400004.

[2] Definitions|Suicide|Violence Prevention|Injury Center|CDC; n.d. https://www. cdc.gov/violenceprevention/suicide/definitions.html. [Accessed 4 February 2017]. 
[3] Baca-García E, Diaz-Sastre C, Basurte E, Prieto R, Ceverino A, Saiz-Ruiz J, et al. A prospective study of the paradoxical relationship between impulsivity and lethality of suicide attempts. J Clin Psychiatry 2001;62:560-4.

[4] Hawton K, van Heeringen K. Suicide. Lancet 2009;373:1372-81, doi:http://dx. doi.org/10.1016/S0140-6736(09)60372-X.

[5] Ostamo A, Lönnqvist J. Excess mortality of suicide attempters. Soc Psychiatry Psychiatr Epidemiol 2001;36:29-35.

[6] Levinson D, Haklai Z, Stein N, Gordon E-S. Suicide attempts in Israel: age by gender analysis of a national emergency departments database. Suicide Life Threat Behav 2006;36:97-102.

[7] Weyrauch KF, Roy-Byrne P, Katon W, Wilson L. Stressful life events and impulsiveness in failed suicide. Suicide Life Threat Behav 2001;31:311-9, doi: http://dx.doi.org/10.1521/suli.31.3.311.24240.

[8] Geddes JR, Juszczak E, O'Brien F, Kendrick S. Suicide in the 12 months after discharge from psychiatric inpatient care, Scotland 1968-92. J Epidemiol Community Health 1997;51:430-4.

[9] Goldacre M, Seagroatt V, Hawton K. Suicide after discharge from psychiatric inpatient care. Lancet (London, England) 1993;342:283-6, doi:http://dx.doi. org/10.1016/0140-6736(93)91822-4.

[10] Qin P, Nordentoft M. Suicide risk in relation to psychiatric hospitalization: evidence based on longitudinal registers. Arch Gen Psychiatry 2005;62:42732, doi:http://dx.doi.org/10.1001/archpsyc.62.4.427.

[11] Yaseen ZS, Kopeykina I, Gutkovich Z, Bassirnia A, Cohen LJ, Galynker II. Predictive validity of the suicide trigger scale (STS-3) for post-discharge suicide attempt in high-risk psychiatric inpatients. PLoS One 2014, doi:http:// dx.doi.org/10.1371/journal.pone.0086768.

[12] Yaseen ZS, Galynker II, Cohen LJ, Briggs J. Clinicians' conflicting emotional responses to high suicide-risk patients-association with short-term suicide behaviors: a prospective pilot study. Compr Psychiatry 2017, doi:http://dx.doi. org/10.1016/j.comppsych.2017.03.013.

[13] Pirkola S, Sohlman B, Wahlbeck K. The characteristics of suicides within a week of discharge after psychiatric hospitalisation-a nationwide register study. BMC Psychiatry 2005;5:32, doi:http://dx.doi.org/10.1186/1471-244X-5-32.

[14] Department of Psychiatry; University of Michigan. Continuity of Care for Suicide Prevention and Research. 2011.

[15] Waterhouse J, Platt S. General hospital admission in the management of parasuicide: a randomised controlled trial. Br J Psychiatry 1990;156:236-42.

[16] van der Sande R, van Rooijen L, Buskens E, Allart E, Hawton K, van der Graaf Y, et al. Intensive in-patient and community intervention versus routine care after attempted suicide. A randomised controlled intervention study. Br J Psychiatry 1997; 171:35-41.

[17] Fleischmann A, Bertolote JM, Wasserman D, De Leo D, Bolhari J, Botega NJ, et al. Effectiveness of brief intervention and contact for suicide attempters: a randomized controlled trial in five countries. Bull World Health Organ 2008;86:703-9.

[18] Miller IW, Camargo CA, Arias SA, Sullivan AF, Allen MH, Goldstein AB, et al. Suicide prevention in an emergency department population: the ED-SAFE study. JAMA Psychiatry 2017;74(6):563-70, doi:http://dx.doi.org/10.1001/ jamapsychiatry.2017.0678.
[19] Gysin-Maillart A, Schwab S, Soravia L, Megert M, Michel K. A novel brief therapy for patients who attempt suicide: a 24-months follow-Up randomized controlled study of the attempted suicide short intervention program (ASSIP). PLoS Med 2016;13:e1001968, doi:http://dx.doi.org/10.1371/journal. pmed.1001968.

[20] Lawrence RE, Oquendo MA, Stanley B. Religion and suicide risk: a systematic review. Arch Suicide Res 2016;20:1-21, doi:http://dx.doi.org/10.1080/ 13811118.2015.1004494.

[21] Israel Ministery of Health. Suicides and Suicide attemtps rates in Israel. 2016.

[22] Shelef L, Kaminsky D, Carmon M, Kedem R, Bonne O, Mann JJ, et al. Risk factors for suicide attempt among Israeli Defense Forces soldiers: a retrospective case-control study. J Affect Disord 2015;186:232-40, doi:http://dx.doi.org/ 10.1016/j.jad.2015.07.016.

[23] Shelef L, Tatsa-Laur L, Derazne E, Mann JJ, Fruchter E. An effective suicide prevention program in the Israeli Defense Forces: a cohort study. Eur Psychiatry 2016;31:37-43, doi:http://dx.doi.org/10.1016/j.eurpsy.2015.10.004.

[24] Gilat I, Shahar G. Suicide prevention by online support groups: an action theory-based model of emotional first aid. Arch Suicide Res 2009;13:52-63, doi:http://dx.doi.org/10.1080/13811110802572148.

[25] Raymond B, Flannery Jr. PD, George S, Everly Jr. PD. Crisis intervention: a review. Int J Emerg Ment Health 2000;119.

[26] Brunstein Klomek A, Nakash O, Goldberger N, Haklai Z, Geraisy N, Yatzkar U, et al. Completed suicide and suicide attempts in the Arab population in Israel. Soc Psychiatry Psychiatr Epidemiol 2016;51:869-76, doi:http://dx.doi.org/ 10.1007/s00127-016-1219-2.

[27] Carter GL, Clover K, Whyte IM, Dawson AH, D’Este C. Postcards from the EDge: 24-month outcomes of a randomised controlled trial for hospital-treated selfpoisoning. Br J Psychiatry 2007;191:548-53, doi:http://dx.doi.org/10.1192/bjp. bp.107.038406.

[28] Levinson D, Ifrah A. The robustness of the gender effect on help seeking for mental health needs in three subcultures in Israel. Soc Psychiatry Psychiatr Epidemiol 2010;45:337-44, doi:http://dx.doi.org/10.1007/s00127-009-00794.

[29] Galdas PM, Cheater F, Marshall P. Men and health help-seeking behaviour: literature review. J Adv Nurs 2005;49:616-23, doi:http://dx.doi.org/10.1111/ j.1365-2648.2004.03331.x.

[30] Oliver MI, Pearson N, Coe N, Gunnell D. Help-seeking behaviour in men and women with common mental health problems: cross-sectional study. Br J Psychiatry 2005;186:297-301, doi:http://dx.doi.org/10.1192/bjp.186.4.297.

[31] Farbstein I, Mansbach-Kleinfeld I, Auerbach JG, Ponizovsky AM, Apter A. The Israel Survey of Mental Health among Adolescents: prevalence of attentiondeficit/hyperactivity disorder, comorbidity, methylphenidate use, and helpseeking patterns. Isr Med Assoc J 2014;16:568-73.

[32] Flaskerud JH. The effects of culture-compatible intervention on the utilization of mental health services by minority clients. Community Ment Health J 1986;22:127-41.

[33] Snowden LR, Hu TW, Jerrell JM. Emergency care avoidance: ethnic matching and participation in minority-serving programs. Community Ment Health J 1995;31:463-73. 